\title{
DAMPAK BANTUAN INDONESIA TERHADAP \\ NEGARA ANGGOTA KERJA SAMA SELATAN-SELATAN DI KAWASAN ASIA
}

\author{
Ayu Rachmawaty \\ Fakultas Ilmu Sosial dan Ilmu Politik, Universitas Muhammadiyah Malang \\ Email: ayurachmawaty99@gmail.com \\ Ade Rachmaliani \\ Fakultas Ilmu Sosial dan Ilmu Politik, Universitas Muhammadiyah Malang \\ Ahmad Rizaldi \\ Fakultas Ilmu Sosial dan Ilmu Politik, Universitas Muhammadiyah Malang
}

\begin{abstract}
South South Cooperation (SSC) is a form of development cooperation between developing countries based on the principle of solidarity, equality (mutual opportunity) and the principle of mutual benefit. Indonesia is one of the member countries of Cooperation which is active as a foreign aid provider for SSC partner countries. So far, the available discussions have only focused on the benefits of South South Cooperation (SSC) on Indonesia's national interests. This journal examines from another perspective on the impact of Indonesia's foreign assistance on the development of member states of South South Cooperation. The research method used was descriptive qualitative with a focus on providing assistance in the Asian region. Foreign aid provided by Indonesia focuses more on training and community empowerment programs. Indonesia also provided financial assistance but the value was no greater than non-financial assistance worth US $\$ 60$ million. In addition, Indonesia's foreign aid for conflict countries in Asia includes educational, economic, health and social programs that aim to help and alleviate the suffering of people in the midst of conflict. The impact of the provision of non-financial assistance is that people in developing countries in Asia get new knowledge, skills and information to be implemented in their countries and increase community empowerment so that they are not increasingly dependent on foreign financial assistance.
\end{abstract}

Keywords: South South Cooperation (SSC), Indonesian Foreign Aid, Programs and Training 


\begin{abstract}
Abstrak
Kerja Sama Selatan Selatan (KSS) merupakan bentuk kerja sama pembangunan antara negara - negara berkembang yang berlandaskan prinsip solidaritas, kesetaraan (mutual opportunity) dan prinsip saling menguntungkan. Indonesia merupakan salah satu negara anggota Kerja Sama yang aktif menjadi pemberi bantuan luar negeri bagi negara-negara mitra KSS. Selama ini pembahasan yang tersedia hanya berfokus pada manfaat dari Kerja Sama Selatan Selatan (KSS) terhadap kepentingan nasional Indonesia. Jurnal ini mengkaji dari sudut pandang lain mengenai dampak dari bantuan luar negeri Indonesia terhadap perkembangan negara - negara anggota Kerja Sama Selatan Selatan. Metode penelitian yang digunakan adalah kualitatif deskriptif dengan fokus pemberian bantuan di kawasan Asia. Bantuan luar negeri yang diberikan Indonesia lebih berfokus mengenai pelatihan dan program-program pemberdayaan masyarakat. Indonesia juga memberikan bantuan finansial namun nilainya tidak lebih besar dari bantuan non-finansial yang bernilai US\$ 60 Juta. Selain itu bantuan luar negeri Indonesia bagi negara-negara konflik di Asia meliputi program-program pendidikan, ekonomi, kesehatan dan sosial yang bertujuan untuk membantu dan meringankan penderitaan masyarakat yang berada di tengah konflik. Dampak dari pemberian bantuan non-finansial ini adalah masyarakat di negara-negara berkembang Asia tersebut mendapatkan pengetahuan, ketrampilan dan informasi baru untuk diimplemetasikan di negara nya serta meningkatkan pemberdayaan masyarakat agar tidak semakin bergantung terhadap bantuan asing yang bersifat finansial.
\end{abstract}

Kata kunci: Kerja Sama Selatan Selatan (KSS), Bantuan Luar Negeri Indonesia, Program dan Pelatihan. 


\section{Pendahuluan}

\section{Kerja Sama Selatan Selatan (KSS)}

merupakan bentuk kerja sama pembangunan antara negara - negara berkembang yang berlandaskan prinsip solidaritas, kesetaraan (mutual opportunity) dan prinsip saling menguntungkan atau mutual benefit (Tim Koordinasi Nasional KSST Indonesia, 2017). Dalam perkembangannya, Kerja Sama Selatan Selatan menjalin kemitraan yang mendukung pembangunan dan dikenal dengan Kerja Sama Triangular (Triangular Cooperation). Adapun tujuan dari kerja sama ini untuk meningkatkan kesejahteraan dan pembangunan di negara - negara berkembang. Bentuk dari dukungan pembangunan secara individu maupun kolektif di negara - negara berkembang tersebut berupa kerjasama pertukaran pengetahuan, ketrampilan teknis, pelatihan keterampilan dan pertukaran sumber daya (Kokange, 2014). Harapan dari pembentukan Kerja Sama Selatan Selatan ini mampu mewujudkan kemandirian negara berkembang dari bantuan negara maju dan untuk meningkatkan pengaruh negara berkembang di dunia internasional (Choesni, 2014). Awal mula Kerja Sama Selatan Selatan berasal dari pembentukan Konferensi Asia - Afrika (KAA) pada tahun 1955 di Bandung sebagai wujud solidaritas antar negara post - kolonial, kemudian dengan adanya Gerakan Non Blok yang digagas negara Indonesia pada 1961 sebagai wujud prinsip tidak berpihak ke salah satu di antara Blok Barat dan Blok Timur, serta pembentukan Grup 77 pada tahun 1964 (United Nation Background Paper, 2011). Kerja Sama Selatan Selatan dibentuk dengan latar belakang pasca Perang Dunia II yang memunculkan banyak negara - negara yang memerdekakan diri dan berusaha untuk mewujudkan pemerintahan nya secara independen tanpa terikat oleh pihak kolonial sebelumnya. Sebagai negara yang masih "sangat dini", maka negara - negara tersebut memerlukan bantuan dari negara lain yang nantinya akan berkontribusi pada kelanjutan hidup negara - negara baru tersebut. Namun sebisa mungkin mereka meminimalisir keterlibatan bantuan dari negara maju agar tidak terjadinya ketergantungan yang berpengaruh pada ruang gerak negara berkembang itu sendiri.

Indonesia sebagai salah satu negara yang aktif dalam pembentukan embrio Kerja Sama Selatan Selatan melalui perwujudan Konferensi Asia - Afrika dan promoter Gerakan Non - Blok selanjutnya semakin melibatkan diri sebagai salah satu negara donor bantuan luar negeri bagi negara - negara yang terlibat dalam Kerja 
Sama Selatan Selatan bersama dengan negara lain seperti Tiongkok, Brazil dan Afrika Selatan (Pujayanti, 2015). Secara nominal dana, anggaran program bantuan luar negeri Indonesia untuk KSS hanya 10 Juta US Dollar. Hal ini berbeda jauh dengan anggaran bantuan negara Tiongkok, Brazil dan Afrika Selatan yang masing - masing mengalokasikan dana untuk program bantuan KSS sebesar 2 miliar US Dollar, 500 juta US Dollar, dan 118 juta US Dollar (Mc Ray, 2014). Bentuk bantuan yang diberikan Indonesia terhadap negara-negara anggota KSS berupa program - program seperti pada sektor pengembangan sumber daya alam dan good governance terkait pelatihan demokrasi sebab periode transisi pemerintahan Indonesia pada tahun 1998 dianggap sebagai suatu langkah kesuksesan terwujudnya demokrasi sehingga mampu menjadi acuan pembelajaran bagi negara - negara berkembang yang juga mulai mewujudkan transisi pemerintahan menuju demokratis (Pujayanti, 2015). Kemampuan Indonesia sebagai salah satu negara donor telah dipercaya sejak Indonesia tergabung dalam anggota negara G-20 setelah status negara ini naik menjadi Middle Income Country (MIC). Indonesia merupakan negara yang memiliki tingkat pertumbuhan ekonomi terbesar keenam di antara negara-negara berkembang di dunia, dan pada 2010 menjadi negara yang memiliki tingkat pertumbuhan ekonomi tercepat di antara negara-negara anggota G-20 (Juned \& Saripudin, 2017).

Dari situlah peran dari Indonesia semakin berkembang dalam dunia Internasional tak terkecuali dalam Kerja Sama Selatan Selatan (KSS). Sebagai wujud nyata partisipasi Indonesia dalam Kerja Sama Selatan Selatan akhirnya dibentuklah sebuah lembaga yang bernama Indonesia Technical Cooperation Program (ITCP) pada tahun 1981 yang bertujuan untuk memberikan program - program bantuan luar negeri kepada semua negara berkembang. Program yang diberikan baik berupa pelatihan, kunjungan studi, pengiriman tenaga ahli dan lain sebagainya (https://isstc.setneg.go.id/).

Motivasi dari pembuatan jurnal ini disebabkan kebanyakan tulisan - tulisan akademik hanya memfokuskan bagaimana Kerja Sama Selatan Selatan (KSS) memberikan manfaat bagi Indonesia atau mewujudkan tujuan diplomasi yang hendak dicapai oleh Indonesia, serta membahas mengenai bagaimana peran Indonesia dapat semakin eksis di kancah Internasional melalui kontribusi nya pada Kerja Sama Selatan Selatan. Oleh karena itu tulisan ini justru hendak mengkaji dari sudut pandang yang lain mengenai 
bagaimana dampak signifikan dari bantuan luar negeri Indonesia terhadap perkembangan negara - negara anggota Kerja Sama Selatan Selatan? Sebab yang menarik untuk dikaji disini adalah secara nominal dana, anggaran bantuan luar negeri Indonesia untuk negara-negara KSS tidak sebesar negara seperti Tiongkok, Brazil dan Afrika Selatan. Oleh karena itu diperlukan tulisan akademik yang mengkaji signifikansi dari bantuan luar negeri Indonesia terhadap negara - negara berkembang anggota KSS, terlepas dari besar kecil nya nominal anggaran yang telah dibuat oleh pemerintah Indonesia.

\section{Persentanse Negara Peserta bedasarkan Kawasan}

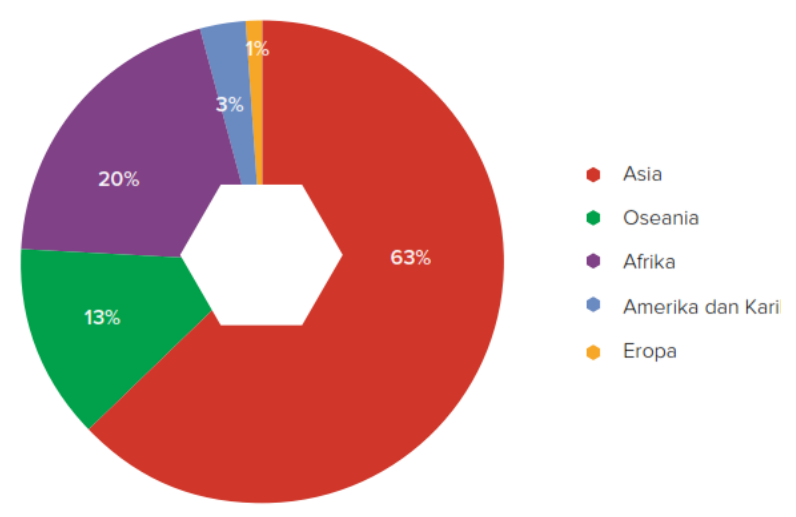

Sumber: Laporan Tahunan Kerja Sama Selatan-Selatan dan Triangular (KSST) Indonesia 2016

Jurnal ini memfokuskan pada pemberian bantuan luar negeri Indonesia pada periode kurun waktu 2015-2019. Alasan dari pengambilan periode tersebut dikarenakan Indonesia berperan sebagai part of the solution bagi beragam masalah global. Dalam Rencana Strategis Kementerian Luar Negeri (Kemlu) 20152019 disebutkan bahwa kebijakan luar negeri Indonesia menempatkan prioritas terhadap isu yang terkait kepentingan masyarakat yaitu: isu perdamaian, peningkatan kualitas perlindungan WNI di luar negeri, lingkungan hidup, demokrasi dan HAM, serta Kerja Sama Selatan Selatan yang menjadi fokus pembahasan dalam jurnal ini (Rencana Strategis (Renstra) Kementerian Luar Negeri Republik Indonesia 2015-2019). Dalam periode ini terdapat sejumlah kerjasama penting dan bantuan yang diberikan Indonesia terhadap negara - negara mitra KSS terutama bantuan yang bersifat teknis seperti pelatihan maupun pengiriman tenaga ahli. Sejak program pemberian bantuan ini diselenggarakan pada 2006, negara - negara KSS yang menjadi penerima bantuan luar negeri Indonesia mengalami peningkatan serta jumlah kegiatannya setiap tahunnya. Oleh karena itu salah satu sasaran pembangunan bidang politik luar negeri Indonesia di periode 2015-2019 mencantumkan poin "menguatnya peran Indonesia dalam Kerja Sama Selatan Selatan dan Triangular" (Rencana Strategis (Renstra) Kementerian Luar Negeri Republik 
Indonesia 2015-2019). Fokus kawasan dari negara - negara mitra KSS yang menerima bantuan luar negeri Indonesia adalah Asia. Alasan dari fokus ke kawasan Asia ini dikarenakan berdasarkan data diketahui bahwa kawasan Asia adalah kawasan terbesar negara - negara mitra KSS yang menerima bantuan luar negeri Indonesia termasuk di dalamnya negara - negara Timur Tengah seperti Palestina dan Afghanistan.

\section{Metode Penelitian}

Dalam penulisan jurnal ini menggunakan unit analisis negara dimana negara - negara yang dianalisa adalah negara Indonesia sebagai negara pendonor bantuan luar negeri dan negara - negara berkembang di kawasan Asia yang menjadi mitra Kerja Sama Selatan Selatan (KSS) sekaligus penerima bantuan luar negeri Indonesia. Unit analisis ini dipilih sebab kedua kelompok negara tersebut merupakan variabel utama yang akan menjawab rumusan permasalahan dari jurnal ini. Alasan dari pemilihan negara Indonesia sebagai variabel yang dibahas dalam jurnal ini dikarenakan perlu adanya penulisan lebih lanjut mengenai hubungan Indonesia dengan negara - negara mitra Kerja Sama Selatan - Selatan dari sudut pandang yang berbeda. Jenis penelitian yang digunakan dalam jurnal ini adalah penelitian kualitatif deskriptif yang dimana jurnal ini akan mendeskripsikan mulai dari bentuk - bentuk bantuan luar negeri Indonesia terhadap negara mitra KSS, program apa saja yang dijalankan oleh Indonesia, lalu dampak apa dari bantuan luar negeri Indonesia terhadap perkembangan negara - negara mitra KSS. Penelitian kualitatif deskriptif dipilih sebab jenis penelitian ini mampu memberikan penjelasan secara keseluruhan dan komprehensif sehingga mampu memberikan rincian terhadap topik yang sedang dibahas. Dalam mendukung tulisan jurnal ini penulis menggunakan jenis data primer (melalui website resmi Indonesia South - South Technical Cooperation https://isstc.setneg.go.id/) dan juga data data sekunder yang berasal dari jurnal, publikasi akademik, buku, berita, dan segala sumber yang mendukung tentang topik pembahasan jurnal ini.

Teknik pengumpulan data dalam penulisan jurnal ini menggunakan teknik internet-based research yang dimana sumber - sumber data primer maupun sekunder didapatkan dari hasil pencarian melalui internet. Melalui sumber - sumber inilah informasi akan diolah menjadi literature review sebagai pondasi dari hasil dan pembahasan yang akan dibahas di bagian selanjutntya. 


\section{Literature Review}

\section{Bentuk bantuan luar negeri Indonesia untuk negara anggota KSS}

Dalam KSS, Indonesia dianggap memiliki power di antara negara negara regional atas kepentingan dan tanggung jawabnya sebagai negara yang turut ikut dalam KSS dengan memberikan bantuan finansial dan program - program (Choesni, 2014). Indonesia menaruh komitmennya terhadap KSS dengan cara mencantumkan KSS dalam Rencana Pembangunan Jangka Menengah Nasional (RPJMN) sejak tahun 2010 guna memperkuat peran Indonesia dalam forum kerjasama pembangunan internasional (Prakoso \& Abdurrachman, 2017). Dibandingkan dengan negara lainnya, bantuan finansial berupa dana dari Indonesia hanya sebesar 10 juta dollar AS, jika dibandingkan dengan negara lain seperti Tiongkok, Brazil India yang menyumbang ratusan juta untuk KSS, dapat dikatakan bahwa Indonesia menyumbang dengan jumlah paling kecil (Pujayanti, 2015) Oleh karena itu, bantuan yang diberikan Indonesia cenderung berbentuk bantuan non finansial. Bentuk bantuan yang dimaksud adalah seperti bantuan program-program yang menunjukkan kepentingan nasional pada negara negara lain yang berifat karakteristik, politis, dan pencitraan atas kedudukan Indonesia pada saat itu sebagai satu satunya anggota tetap G20 di antara negara negara ASEAN lainnya (Prakoso \& Abdurrachman, 2017). Pada saat Indonesia aktif dalam memberikan bantuan kepada sesama negara berkembang, Indonesia mempromosikan demokrasi karena keberhasilan Indonesia menjadi negara demokrasi pada tahun 1998 kepada negara negara yang masih dalam proses transisi demokrasi. Selain itu, bentuk kerjasama yang dilakukan oleh Indonesia dengan KSS adalah bantuan berupa hibah atau hadiah dan memberikan beberapa pelatihan tenaga kerja bagi negara anggota KSS, seperti tenaga ahli dalam bidang pertanian, perikanan, good government dan UKM. Total anggaran pemerintah Indonesia untuk bantuan KSS bernilai sebesar 15,08 juta US Dollar pada tahun 2016 (Laporan Tahunan Kerja Sama Selatan -Selatan dan Triangular (KSST) Indonesia, 2016). Terlibatnya Indonesia di dalam KSS, dapat membantu pembangunan negara yang tertinggal, selain itu bantuan yang diberikan oleh Indonesia menjadi jalan Indonesia untuk berinvestasi dalam dunia politik dan ekonomi, karena dengan KSS, Indonesia dapat menembus pasar produk barang dan jasa dari Indonesia di pasar global (Pujayanti, 2015; Prakoso \& Abdurrachman, 2017). 
Menurut kedua referensi tersebut, selain sebagai negara penerima bantuan, Indonesia sangat aktif sebagai negara pemberi bantuan, terutama program, tenaga kerja. Tentu, dengan memberikan banyak bantuan Indonesia memiliki kepentingan. Pada jurnal "Peran Indonesia dalam Kerjasama Selatan - Selatan dan Triangular" dijelaskan bahwa bantuan yang diberikan oleh Indonesia untuk KSS juga menguntungan untuk beberapa aspek bagi Indonesia, baik itu politik dan ekonomi untuk negara Indonesia. Pada jurnal "Kerja Sama Selatan - Selatan dan Manfaatnya bagi Indonesia" juga masih menjelaskan manfaat dan dampak bagi Indonesia atas bantuan yang diberikan oleh Indonesia untuk negara negara anggota KSS, salah satunya kepentingan politik Indonesia yang mengharapkan politik luar negeri Indonesia kuat atas pelaksanaannya. Kedua jurnal tersebut belum menjelaskan apa dampak atau manfaat yang didapat oleh negara negara anggota atas bantuan yang diberikan oleh Indonesia.

Dalam referensi selanjutnya dijelaskan bahwa Indonesia menjadikan negara Palestina sebaagai negara prioritas penerima bantuan sejak tahun 2006 hingga tahun 2014. Bantuan yang diberikan Indonesia berupa bantuan teknis seperti pembangunan pusat jantung Indonesia di Rumah sakit Al- Shifa dan ada juga bantuan berupa kerja sama Teknik dari Direktorat Kerjasama Teknik (Apresian, 2016). Selain itu, melalui organisasi kemanusiaan, Aksi Cepat Tanggap (ACT), Indonesia memberikan beberapa bantuan pada bidang Pendidikan Ekonomi, Kesehatan dan Sosial. Dalam aspek Pendidikan, Indonesia memberikan School of Disability yang merupakan sekolah untuk anak anak yang memiliki kebutuhan khusus. Selain itu Indonesia juga memberikan Program Beasiswa bagi mahasiswa Palestina, selain itu dalam bidang perekonomian, Indonesia juga memberikan perahu untuk berjalannya pekerjaan bagi para nelayan, Chicken Farm Program, dll. Berbeda dengan bantuan langsung pemerintah, ACT memberikan bantuan Jabalia Medical Centre, Bantuan peralatan P3K, dan bantuan mobil ambulance dan juga bantuan khusus untuk ibu hamil. Terakhir, dalam bidang sosial, Indonesia memberikan bantuan berua Green House, Olive Tree Planting, Baju hangat yang dapat digunakan padasaat musim dingin, Humanity Card, dll (https://act.id/palestina/). Alasan Indonesia untuk memprioritaskan Palestina sebagai negara penerima bantuan adalah karena isu konflik yang terjadi di Palestina yang sampai sekarang disebabkan Palestina masih berjuang untuk mencapai 
kemerdekaannya dari Israel. Isu kemerdekaan inilah yang menjadi agenda penting untuk Indonesia, yang sekaligus menjadi kepentingan politis Indonesia (https://act.id/palestina/).

Selain Palestina, Indonesia juga memberikan bantuan kepada negara negara lainnya. Pada annual report KSS Indonesia pada tahun 2016, tercatat sebanyak 86 bantuan untuk negara Kawasan Asia yaitu, Timor Leste 15 program, Fiji 14 Program, Papua Nugini 12 program, 10 program untuk masing masing negara Myanmar dan Malaysia, Bangladesh 9 program, Afghanistan dan Kamboja juga sama sama menerima 8 program bantuan dari Indonesia. Dari catatan penerima program bantuan Indonesia, Asia masih dominan, karena pada dasarnya negara negara di Kawasan Asia masih banyak negara negara berkembang. Berdasarkan data yang tertera pada annual report ini, bantuan paling besar yang dilakukan oleh Indonesia adalah program pelatihan keterampilan untuk tenaga kerja pada setiap negara (Laporan Tahunan Kerjasama Selatan - Selatan dan Triangular Indonesia, 2016).

$$
\text { Dalam "Laporan Tahunan }
$$

Kerjasama Selatan - Selatan dan Triangular Indonesia 2016" juga dijelaskan beberapa program unggulan yang dimiliki
Indonesia untuk negara anggota KSS di kawasan Asia ini, seperti :

\section{a.) Sharing Best Practices and}

\section{Experience on Women and Leadership}

Kegiatan ini dilakukan dalam rangka untuk tercapainya salah satu goals pada program Sustainable Development Goals tentang kesetaraan gender nomor 5. Goals pada SDGs ini berisi mengenai kampanye kesetaraan gender lalu pemberdayaan perempuan untuk mengatasi adanya kesenjangan gender di setiap negara yang berada di negara naungan PBB. Program ini diselenggarakan di Surabaya oleh Kementrian Pemberdayaan Perempuan dan Perlindungan Anak (Kemen PPPA) dalam konteks kerangka Kerjasama Selatan Selatan (KSS), Indonesia berkolaborasi bersama dengan Colombo Plan dalam menjalankan Colombo Plan Gender Affairs Program dengan judul Sharing Best Practices on Women and Leadership. Program ini diikuti oleh 14 negara, seperti Vietnam, Indonesia, Bangladesh, Myanmar, Malaysia. Program ini merupakan penyediaan wadah bagi peserta agar kaum perempuan juga memiliki hak untuk berbagi strategi, inisiatif, tantangan keuntungan dan isu dalam mempromosikan perempuan yang berperan dan terlibat dalam perubahan 
sosial, misalnya menjadikan wanita untuk memiliki hak menjadi seorang pemimpin.

\section{b.) OIC Workshop on Vaccine}

\section{Management}

Selain program mengenai pemberdayaan wanita, Indonesia juga memberikan bantuan yang masih dibawah naungan Kerjasama Selatan Selatan mengenai vaksinasi, vaksinasi yang menjadi salah satu aspek paling penting dalam kesehatan manusia, yang menjadi salah satu upaya agar berkurangnya ancaman dari penyakit, seperti TBC, polio, cacar yang merupakan salah satu penyakit yang cukup parah bagi manusia. Program ini diselenggarakan melalui BUMN Bio Farma. Indonesia dianggap sebagai negara yang memiliki teknologi vaksinasi yang cukup unggul. Keunggulan yang dimiliki adalah pengalaman dalam memproduksi selama 126 tahun dan produknya sudah diakui oleh Organisasi Kesehatan Dunia (OKD). Kegiatan workshop tentang pengenalan vaksin ini didukung oleh Badan Pengawas Obat dan Makanan (BPOM) dan Dirjen Pencegahan dan Pengendalian Penyakit dari Kementrian Kesehatan yang dihadiri oleh beberapa negara salah satunya yang berasal dari negara Asia seperti Malaysia, Bangladesh, dll. Program ini memperkenalkan vaksinasi kepada negara negara yang turut hadir mengenai fungsi tentang vaksinasi dan penggunaannya yang diaplikasikan di negara negara Islam untuk kesehatan manusia.

Selain memberikan program seperti workshop dalam KSS, Indonesia juga memberikan bantuan secara fisik untuk Suku Rohingya di Myanmar atas konfliknya yang terjadi dengan pemerintahan Myanmar berupa kapal kemanusiaan untuk mengangkut segala bantuan dari Indonesia menuju Myanmar. Selain itu Indonesia juga memberikan bantuan Humanity Card. Humanity Card yang juga diterima oleh Palestina merupakan sebuah program berupa kartu untuk memberikan kemuahan para kaum Rohingya yang menerima bantuannya. Selanjutnya bantuan yang diberikan oleh ACT adalah Integrated Community Shelter yang berupa seperti hunian secara sementara bagi kaum pengungsi (https://act.id/rohingya/).

\section{Pembahasan}

Dampak Terhadap Negara - Negara Anggota Kerjasama Selatan-Selatan Sebagai Penerima Bantuan Luar Negeri Indonesia

Sejak kurang lebih 60 tahun didirikannya kerjasama selatan-selatan (KSS), Indonesia merupakan salah satu negara anggota yang terlibat aktif dalam memberikan sumbangsih terhadap negara- 
negara yang tergabung dalam kerjasama tersebut. Dalam Triangular Cooperation and Aid Effectiveness, Fredelone menjelaskan bahwa semakin majunya perkembangan zaman kerjasama pembangunan internasional semakin meningkat seiring dengan meningkatnya peran-peran negara berpenghasilan menengah bukan hanya sebagai penerima bantuan, akan tetapi juga sebagai pemberi bantuan (Prakoso dan Abdurrachman, 2017). Bantuan yang diberikan oleh Indonesia untuk negara-negara berkembang yang berada dalam kawasan kerjasama terebut biasanya berupa hibah dan berbagai bentuk pelatihan yang diantaranya pelatihan dalam bidang pertanian, perikanan, good government serta UKM. Dalam sepuluh tahun terakhir ini, Indonesia telah mengadakan lebih dari 700 program KSS yang bernilai di atas US\$ 60 juta dengan mitra negara-negara berkembang di Asia, Afrika dan Pasifik Selatan (Pujayanti, 2015).

Salah satu program unggulan KSS adalah "Sharing Best Practices and Experience on Women and Leadership". Tujuan dari diadakannya kegiatan ini adalah untuk memfasilitasi peserta dari negara-negara yang tegabung dalam kerjasama Selatan-Selatan untuk saling berbagi informasi, strategi, masalah sekaligus tantangan dalam isu kepemimpinan dan keterlibatan perempuan dalam perubahan sosia secara global. Yang mana program tersebut berbentuk workshop yang diikuti oleh beberapa perwakilan 14 negara anggota Colombo Plan di wilayah Asia Pasifik yang mencakup Bangladesh, Bhutan, Filipina, Fiji, Indonesia, Iran, Malaysia, Maladewa, Myanmar, Nepal. Pakistan, Sri Lanka, dan Vietnam (Laporan Tahunan Kerjasama Selatan-Selatan dan Triangular Indonesia, 2016). Dampak diadakannya workshop dari program ini adalah para peserta workshop memperoleh pengalaman dan pembelajaran dari pengalaman Indonesia dalam memberdayakan perempuan di negaranya yang kemudian para peserta diharapkan dapat menerapkan pengalaman dan kepemimpinan tersebut di masingmasing negara. Tidak hanya itu, ada pula program kegiatan workshop yang diselenggarakan oleh Indonesia yang mana merupakan salah satu program andalan dari KSS juga, kegiatan workshop tersebut ialah "OIC Workshop on Vaccine Management" yang ditujukan untuk membahas tentang metode apa saja yang diperlukan untuk menghasilkan vaksin yang aman, berkualitas dan memiliki efektivitas yang ampuh (Laporan Tahunan Kerjasama Selatan-Selatan dan Triangular Indonesia, 2016). Adapun dampak dari diadakannya workshop tersebut adalah 
munculnya sebuah gagasan baru untuk mengubah dan membangun kemandirian negara-negara peserta dalam memproduksi vaksin yang kemudian memiliki keampuhan untuk kesehatan manusia.

Dengan berperan aktif dalam kerjasama selatan-selatan terutama dalam bantuan kemanusiaan, posisi Indonesia semakin diperhitungkan di dunia internasional sehingga mempermudah pencapaian kepentingan nasional, sedangkan dampak positif yang ditimbulkan dari adanya kerjasama mutual ini yakni meningkatkan hubungan bilateral diantara penerima dan pemberi bantuan tersebut dan dampak negatif dari kerjasama ini adalah dari penerima bantuan, negara penerima bantuan kemungkinan akan menjadi ketergatungan kepada negara lain terutama negara yang memberikan bantuan.

Dalam kerjasama Selatan-Selatan ini Indonesia telah banyak memberikan bantuan ke negara-negara yang berada di kawasan Asia, negara yang menerima bantuan tersebut di antarnya India, Bangladesh, Malaysia, Filipina, Singapura, Sri Lanka, Thailand, Vietnam Timor Leste, Fiji, Papua Nugini, Afganistan dan juga Kamboja. Dengan adanya bantuan luar negeri yang diberikan oleh Indonesia terhadap negara-negara yang terletak dibagian kawasan Asia tersebut maka beberapa sektor seperti perekonomian, keamanan di negara-negara yang menerima bantuan tersebut semakin meningkat dan munjukkan perkembangan yang lebih baik. Di sisi lain dengan adanya kerjasama selatan-selatan, perkembangan yang lebih baik tidak hanya ditunjukkan oleh negara yang menerima bantuan saja, akan tetapi negara-negara yang juga memberikan bantuan. Keadaan ekonomi global yang saat ini mengalami ketegangan perdagangan dan ketidakpastian dalam perang tarif memberikan konsekuensi terhadap pasar. Terjadinya peningkatan signifikan pada tarif impor tentu semakin menekan kinerja ekspor, hal-hal seperti itulah yang kemudian menuntut pentingnya kerjasama Selatan-Selatan agar tidak hanya berfokus pada sektor keamanan serta politik saja tetapi juga sektor perekonomian, terutama untuk menciptakan respon serta strategi dalam menangani berbagai situasi yang terjadi.

Pada dasarnya setiap kerjasama pasti menimbulkan keuntungan bagi pihak-pihak yang terlibat didalamnya, dan dalam kerjasama selatan-selatan ini keuntungan yang lebih besar tentu dirasakan oleh negara penerima bantuan,era globalisasi yang telah kita alami saat ini memunculkan berbagai peluang kerjasama dalam berbagi sektor, peluang kerjasama tersebut merupakan 
kesempatan penting yang dibutuhkan oleh setiap negara di dunia. Kerjasama negaranegara berkembang inilah yang kemudian diharapkan memberi dan mencapai peluang tersebut.perlu diingat kembali bahwa dalam kerjasama selatan-selatan negara-negara yang menerima bantuan merupakan negara yang pada umumnya belum berkembang dan cendrung memilik tingkat perekonomian yang rendah. Selain negara-negara di kawasan Asia yang menerima bantuan dari Indonesia memberikan bantuan pula ke negeranegara yang sedang mengalami konflik, salah satunya Palestina. Palestina sendiri menjadi negara penerima banyak bantuan dari Indonesia, dan bantuan dari Indonesia yang diberikan baru-baru ini ialah bantuan kemanusiaan berupa dana sebesar USD1 juta atau sekitar Rp 14 miliar untuk pengungsi Palestina yang pernah tinggal di Gaza di daerah Jerash Camp, Yordania (Hasan, 2019). Bantuan yang diberikan oleh Indonesia sendiri tentu saja berdampak baik bagi palestina, dengan datangnya bantuan dana tersebut para pengungsi palestina di Gaza mendapatkan asupan makanan, gizi dan kesehatan yang lebih baik.

Selain memberikan bantuan ke Palestina, Indonesia juga memberikan bantuan kemanusiaan ke negara yang sekarang masih mengalami gejolak.
Seperti Suriah dan Myanmar yang saat ini tengah mengalami konflik yang menimbulkan banyak korban didalamnya, oleh karena itulah permasalah ini yang menjadikan fokus Indonesia dalam memberikan bantuan kemanusiaan ke kedua negara yang tengah mengalami konflik tersebut. Bantuan tersesebut diwujudkan melalui berbagai bantuan luar negeri Indonesia dan juga organisasiorganisasi kemanusiaan yang salah satunya organisasi kemanusiaan ACT (Aksi Cepat Tanggap) yang dalam organisasi tersebut memilik berbagai program di dalamnya, program-program tersebut meliputi pendidikan, ekonomi, keseharan dan sosial yang mana untuk membantu dan meringankan penderitaan masyarakat yang berada di tengah konflik (https://act.id/program)

Dari pemaparan di atas, Indonesia memang telah mengambil keputusan yang tepat untuk memberikan bantuan luar negeri yang mayoritas berbentuk non finansial seperti pelatihan dan programprogram. Hal ini disebabkan bantuan finansial luar negeri yang diberikan suatu negara akan menimbulkan ketergantungan bagi negara penerima bantuan luar negeri tersebut seperti yang dikemukakan oleh Theotonio Des Santos (Emeh, 2013). Bantuan luar negeri yang paling rawan adalah berupa bantuan finansial yang 
kemudian menjadi bagi negara penerima bantuan akan menjadi sebuah utang negara, dan akan berdampak pada APBN dari negara penerima bantuan dan menjadi beban dalam pelunasan utang negara, oleh karena itu akan menyebabkan menurunnya pengolahan dana lain untuk pengeluaran yang lebih penting seperti pendidikan, kesehatan, lingkungan, kesejahteraan dan lain sebagainya dan pada akhirnya akan menimbulkan kesengsaraan untuk masyarakat di negara tersebut. Oleh karena itu, usaha pemberdayaan masyarakat negara berkembang melalui pelatihan dan program-program ditempuh oleh Indonesia agar sesame negara berkembang mampu memiliki kompetensi yang cukup untuk membangun negara nya sendiri tanpa tergantung dengan uluran tangan pihakpihak yang berkepentingan.

\section{Kesimpulan}

Tulisan ini membahas bagaimana dampak dari bantuan yang diberikan oleh Indonesia terhadap negara-negara Asia yang tergabung dalam Kerja Sama Selatan Selatan (KSS). Dalam Kerja Sama Selatan Selatan ini Indonesia telah berkontribusi secara aktif dengan mengadakan mengadakan lebih dari 700 program sebagai bentuk bantuan, dalam memberikan bantuan tersebut Indonesia banyak memberikan bantuan yang mana bantuan

berupa

pelatihan-pelatihan

ataupun bantuan berupa materi. Dari bantuan yang telah diberikan oleh Indonesia tentu tentu berdampak baik bagi negara penerima bantuan, seperti program unggulan KSS berupa kegiatan workshop "Sharing Best Practices and Experience on Women and Leadership" dan "OIC Workshop on Vaccine Management" yang telah diadakan oleh Indonesia dan dari workshop tersebut para peserta yang hadir dari berbagai negara yang tergabung ke dalam Kerja Sama Selatan Selatan mendapatkan informasi, ketrampilan dan pengetahuan baru yang diiharapkan dapat diimplemtasikan oleh seluruh peserta di negara asalnya. Bantuan finansial yang diminimalisir Indonesia selain karena kemampuan bantuan dana Indonesia yang belum sebesar negara-negara donor lain seperti China, India dan Afrika Selatan disebabkan Indonesia lebih mengedepatkan bantuan yang sifatnya memberdayakan masyarakat penerima bantuan luar negeri tersebut. Hal ini merupakan kelebihan dari sifat bantuan Indonesia yang meminimalisir dampak negatif berupa membuka kemungkinan negara penerima bantuan menjadi ketergantungan terhadap bantuan finansial yang masuk ke dalam negaranya. 


\section{Referensi}

Apresian, S.R. (2016). 'Kerjasama Selatan-Selatan dan Triangular Sebagai Instrumen Peningkatan Peran Indonesia di Tingkat Global'. Jurnal Ilmiah Hubungan Internasional: Universitas Katolik Parahyangan, 12 (2).

Choesni , Tb. A. (2014). Kebijakan Kerja sama Pembangunan SelatanSelatan dan Triangular Indonesia. FGD P3DI dengan Direktorat Kerja sama Pembangunan Internasional Kementerian Perencanaan Pembangunan Nasional/BAPPENAS pada tanggal 11 Juni 2014.

Emeh, I.K.J. (2013). Dependency Theory and Africa's Underdevelopment: a Paradigm Shift from PseudoIntellectualism: the Nigerian Perspective. International Journal of African and Asian Studies, 1.

Hasan, R.A. (2019). Indonesia Sumbang $R p 14$ Miliar untuk Pengungsi Palestina. Merdeka, 7 Maret 2019. https://www.merdeka.com/dunia/in donesia-sumbang-rp-14-miliaruntuk-pengungsi-palestina.html [diakses pada 3 April 2019]

Indonesia South South Cooperation. https://isstc.setneg.go.id/ [diakses pada 1 April 2019]
Juned, M \& Saripudin, M.H. (2018). Potency of the Chinindo (China, India, And Indonesia) as World Economy Dynamism and its Influence to Regional Economic Stability. Mandala: Jurnal Hubungan Internasional, 1 (2).

Kokange, J. O. (2014). The Evolution of South-South Cooperation: A Personal Reflection. Global Policy Essay.

Laporan Tahunan Kerja Sama Selatan Selatan dan Triangular (KSST) Indonesia 2016. https://isstc.setneg.go.id/ [diakses pada 22 Maret 2019]

Mc Ray, D. (2014). Membaca Kebijakan Luar Negeri Indonesia. Kompas, 5 Maret

Prakoso, BM \& Abdurrachman, B. (2017). Peran Indonesia dalam Kerjasama Selatan Selatan dan Triangular. Jurnal Tranborders, 1 (1). P-ISSN: 2598-7399 \& E-ISSN: 2598-9200 Program Kemanusiaan, ACT, https://act.id/program diakses pada 3 April

Pujayanti , A. (2015). Kerja Sama SelatanSelatan dan Manfaatnya Bagi Indonesia. Politica, 6 (1).

Rencana Strategis (Renstra) Kementerian Luar Negeri Republik Indonesia 2015-2019. 
https://www.kemlu.go.id/AKIP/Re

ncana\%20Strategis \%20Kemlu\%20

2015-2019.pdf [diakses pada 20

Maret 2019]

Sympathy of Solidarity Rohingya, Aksi

Cepat

Tanggap.

https://act.id/rohingya/. Diakses

pada tanggal 6 April 2019

Tentang Palestina, ACT.

https://act.id/palestina/. Diakses pada tanggal 5 April 2019.

Tim Koordinasi Nasional KSST Indonesia,

2017, Kerja Sama Selatan -

Selatan dan Triangular Indonesia.

https://isstc.setneg.go.id/index.php/

component/content/article/7-

newsletter/219-kerja-sama-selatan-

$\underline{\text { selatan-dan-triangular-indonesia, }}$

diakses pada 27 Maret 2019

United Nation Background Paper. (2011).

"Harnessing the Positive

Contribution of South-South Co-

operation for Least Developed

Countries

Development".https://www.un.org/

en/conf/ldc/pdf/background\%20pa

per\%20on\%20south-

south $\% 20$ cooperation $\% 20$ for $\% 201$

dcs\%20development-final.pdf 